\title{
SOMBRAS DE LA SCHÖNE SEELE HEGELIANA \\ EN EL EPIPSYCHIDION
}

\section{SHADOWS OF HEGELIAN SCHÖNE SEELE IN EPIPSYCHIDION}

\author{
Vicente Llamas RoiG* \\ Pontificia Universidad Antonianum (Murcia)
}

\begin{abstract}
Resumen: El Espíritu es enteramente individual y activo, no una abstracción de la naturaleza humana, y absolutamente vivo, una conciencia cuya existencia consiste en tenerse a si misma por objeto - pontifica Hegel-, que se hace una determinada representación esencial de sí, en gemación como alma, latente inmaterialidad de la materia, vida psíquica difusiva en progreso desde el estado de conciencia oscura que transluce la sensación al imperio unilateral de exacerbados sentimientos de sí, estigmas de desorden en el despliegue del Espíritu, inadaptado a un mundo sistemáticamente organizado y capaz de desprenderse de todo contenido finito. La profética visión del arte como modalidad sensible de expresión de lo no-espiritual al ser asumido imaginariamente por el Espíritu absoluto subyace en el Epipsychidion de Shelley: la vivencia real de lo utópico empieza a difuminar la tensión dialéctica entre lo interno y lo externo, obstructiva de la completa manifestación de la profundidad del Espíritu que engloba ambas delimitaciones.
\end{abstract}

Palabras clave: Espíritu, autoconciencia, alma, devenir.

AвSTRACT: Spirit is entirely individual and active, not an abstraction of the human nature, and it is absolutely alive, a consciousness whose existence consists of having itself as an object. Spirit, Hegel observes, devises a certain essential representation of itself, emerging, firstly, as a soul, latent ideality or immateriality of matter, diffusive psychic life in progress from the state of dark consciousness which reveals sensation to the unilateral empire of exacerbated feelings of itself, stigmas of disorder in the unfolding of Spirit, misfit in a systematically organized world and able to let go of all the finite content. The

\footnotetext{
* Profesor-doctor asociado del departamento Filosofía y Sociedad Pontificia Universidad Antonianum (Murcia). Correo electrónico: vllamasroig@yahoo.es. Códigos identificativos ORCID (0000-0003-4830-3003) y ResearcherID (Q-8121-2018).
} 
prophetic view of art as a sensitive modality of expression of the non-spiritual, since being imaginarily assumed by the absolute Spirit, underlies in Shelley's Epipsychidion: the real experience of the Utopian starts to blur the dialectical tension between inner and outer, obstructive to the complete display of the spirit's depth which includes both boundaries.

KeYwords: Spirit, self-consciousness, soul, becoming.

\section{Introducción}

... Y la tierra estaba desordenada y vacua. Y la tiniebla velaba la faz del abismo, pero el Espíritu absoluto alentaba sobre las aguas, deviniendo sí mismo en el caos. Y el Espíritu se desgarró en bellas almas que deslizaron por la pendiente de la soledad y el ensueńo para envolverlo todo en su fecundidad...

Las figuras del Espíritu que conjura el Idealismo hegeliano tienen densa impronta en la poesía romántica, más allá del angosto ámbito del pietismo y el Sturm und Drang en que hunde su raíz (la imagen y la pasión como lengua materna del género humano, dicta Hamann), brindando anclajes a la nostalgia de los paraísos perdidos (tierra natal que está en todas partes y en ninguna añorada por Novalis) y sirviendo de canal a la mitologización de las fuerzas históricas ${ }^{1}$ y la exaltación patética del yo frente al espíritu racional, un retorno al noûs orektikós adepto al daimon-éthos mítico. La conciencia demiúrgica remisa al lógos-éthos que trocara el anhelo en boúlesis o deseo racional (órexis dianoctiké) cobra espesor sombrío y goza de primitiva inspiración en su virtud fáustica, el ímpetu morboso que soslaya la diferencia entre lo próvido y lo inerme, potencia deponente de la degradación de ese juego del amor consigo mismo que anuncia la vida divina.

\footnotetext{
${ }^{1}$ Hauser, A. (1968). Historia social de la literatura y el arte, II, Madrid: Ediciones Guadarrama, p. 355: «Con el arte hermenéutico del Romanticismo, con su visión para las afinidades históricas y su sensibilidad para lo problemático y lo discutible en la historia, sin embargo, hemos heredado también su misticismo histórico [...], la idea de que los fenómenos históricos no son sino funciones, manifestaciones y encarnaciones de principios independientes [...] La historia aparece como una esfera dominada por fuerzas anónimas, un substrato de ideas más altas que en los fenómenos históricos individuales se expresan sólo de manera imperfecta. Y esta metafísica platónica encuentra expresión no solo en las teorías románticas, pasadas ya de moda, del espíritu popular, la épica popular, las literaturas nacionales y el arte cristiano, sino también en el concepto de la 'intención artística' (Kunstwollen)».
} 
El fervor de la libertad ante el esclavismo industrial y la superación calificada del sufragio censitario incitan a la universalización del lenguaje poético para ungir a las clases más deprimidas (Wordsworth). Una nueva estética cristaliza en la obra imperfecta, inacabada. La poesía universal progresiva, la poesía sentimental que subordina la forma al contenido en su aspiración al absoluto o al infinito (Schiller, Über naive und sentimentalische Dichtung), el rechazo de la forma mecánica neoclásica en favor de la orgánica (innata, fisionomía expresiva de las cualidades ocultas de las cosas-August W. Schlegel-), el desencanto del mundo (Weltschmerz), la reivindicación del Volkgeist, o el recurrente Doppelgänger del Spätromantik (Hoffman, Lenau,...) tienen savia idealista y son los cauces eclécticos de convección de una burguesía ascendente que da medida al hombre en su irreverencia frente a la constante ofensiva aristocrática del racionalismo crítico.

Entre el "platonismo nebuloso" 2 de Mont Blanc o Prometheus Unbound, los surcos del philos heautôi, y la asimetría de la relación microcosmos-macrocosmos en Queen Mab, Percy B. Shelley se debate en un misticismo materialista que sustenta la creencia en la inmortalidad psíquica como una consecuencia de la eternidad del alma cósmica (Soul of Nature) ${ }^{3}$. Desterrado Dios de la visual humana, condenada la religión como religatio desde la «perception of the relation in which we stand to the principle of the universe» ${ }^{4}$, la naturaleza se diviniza en su contemplación (frente a la epistème theoretiké, un theoreîn teopoiético dirigido a la physis), y es en la conjunción del espíritu humano que repta entre idola specus, reo de las sombras anteriores a la paideía («darkness of our prison»), y el organismo sensible en que está inmerso el espíritu universal a través de la tiniebla profanada por manifestación del misterio donde se alcanza el éxtasis estético. La hipótesis de un Espíritu perpetuo elude el acto de creación, la continuidad del

${ }^{2}$ Elliot, T. S. (1968). Función de la poesía y función de la crítica, Barcelona: Seix Barral, p. 101.

${ }^{3}$ Shelley, P. B. (1975). Poetical Works, Oxford: Oxford University Press, p. 769:

"Worthy a soul that claims

It's kindred with eternity"

El alma racional reside en la cabeza del hombre, que imita la forma esférica del mundo, animal perfecto en su unidad (Timeo 30d). La incorruptibilidad del alma humana estaría en

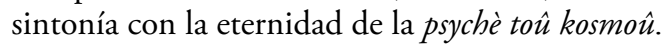

${ }^{4}$ Shelley, P. B. (1975). Poetical Works, p. 811. Cf. Cruzalegui, P. (2001). El platonismo romántico de Shelley, Perú: Pontificia Universidad Católica del Perú, pp. 38ss. Los análisis de Cruzalegui sobre las «veleidades del Shelley extraestético» y su platonismo plotinizado frente al naturalismo poético de Wordsworth o la más elaborada infiltración de la filosofía en el «shaping spirit of Imagination» de Coleridge son sugerentes. 
ser es divina en su misma sucesión ${ }^{5}$; imaginación y fantasía, vertientes suburbiales del nôेs platónico, despejan el ascenso, en subversión gnoseológica, a la belleza intelectual (ópsis tôn adélon tà phainómena), sofocada por el alienante crede ut intelligas de la oscura era del super-yo.

El trono arrebatado al Dios que Blake sacrifica en las aras del «Thou art a man» ${ }^{6}$, el vacío teofánico, es colmado por el poder espiritual y creativo del hombre $^{7}$. La pasión poética cumple en la liturgia de Shelley el papel mediador del Eros en la transición a lo inmortal, función integradora por la que el «todo queda unido consigo mismo» ${ }^{8}$, y la reacción contra la lenidad de una fe que estigmatiza ontológicamente la belleza natural y la soberbia de una razón que repudia el vigor fantasmal de la sombría dignidad estética del horror («Thou Wonder, and thou Beauty, and thou Terror! Thou Harmony of Naturess Art! Thou Mirror» / «Tis the tempestuous loveliness of terror»: un solo rostro para la trinidad ctónica ${ }^{9}$ de la espantosa llanura de Cistene) en la que late el élan vital de un alma dentro del alma pasa por la eclosión del Espíritu en un drenaje idealista de la realidad que este ensayo tratará de rastrear, fondeado en el Epipsychidion.

5 Shelley, P. B. (1975). Poetical Works, pp. 787ss.

${ }^{6}$ Bloom, H. (1974). Los poetas visionarios del romanticismo inglés, Barcelona: Barral Editores, p. 171.

7 Blake, W. (1979). Complete Writings, Oxford: Oxford University Press, p. 793.

${ }^{8}$ Reale, G. (2004). Eros, demonio mediador. El juego de las máscaras en el Banquete de Platón, Barcelona: Herder, p. 252: "lo Bello no es sino el Bien que se manifiesta», y el Uno, lo más elevado en la escalada del Éros, es la medida suprema «que se manifiesta precisamente como lo Bello». Eros sería una "fuerza dinámica y sintética», "auténtica copula mundi» (p. 179), un metaxý entre opuestos, entre lo mortal y lo inmortal, lo humano y lo divino. De estatuto ontológico ambiguo, su doble naturaleza le convierte en daimon impulsor hacia la belleza. Shelley lo declara inductor de la identidad del hombre con la belleza intelectual por defección de la naturaleza propia. Shelley, P. B. (2002). A Defence of Poetry. D. H. Reiman and N. Fraistat (eds.). Shelley's Poetry and Prose, New York/London: W. W. Norton \& Company, p. 517: "The great secret of morals is Love; or a going out of our own nature, and an identification of ourselves with the beautiful which exists in thought, action, or person, not our own".

9 Harrison, J. E. (1903). "The Ker as Gorgon". Prolegomena to the Study to the Greek Religion, Cambridge: Harvard University Press, p. 187: "La forma triple no es primitiva, sino simplemente un ejemplo de una tendencia general ... que hace de cada diosa una trinidad, lo que nos ha dado a las Horas, las Cárites, las Erinias y una multitud de tríos más. Es inmediatamente obvio que las gorgonas no eran realmente tres sino una más dos. Las dos hermanas supervivientes son meros apéndices ... la auténtica gorgona es la Medusa". La tesis de Jane Ellen Harrison es extensible a las Grayas, trinidad que la Prometheia de Esquilo (?) también ubica en la llanura de Cistene. 


\section{Die schöne Seele. Bosquejo psíquico en la Fenomenología del Espíritu}

La primera de las etapas de toma de conciencia del Espíritu por sí mismo en las que se adivina la realidad correspondiente a la idea salda una forma sensible de absoluto plasmada en el arte, permeada por alguna clase de significado íntimo. La profética visión del arte como modalidad sensible de expresión de lo no-espiritual al ser asumido imaginariamente por el Espíritu absoluto subyace en el Epipsychidion de Shelley: la vivencia real de lo utópico difumina la tensión dialéctica entre exterius e interius. El alma autógena es alma natural, de etopeya individual, real en auspicio corpóreo por comunión de lo externo y lo interno en una psychepháneia cósmica.

El yo psicofísico de los ironistas fichteanos, considerado el yo absoluto e incondicionado, eclipsa la objetividad del no-yo, una reprobable fusión de Ich transcendental y conciencia empírica que sella la realidad global. El yo sería la radical negación sin ulterior defoliación del no-yo, mas hay una subjetividad extravagante, pura interioridad que discurre hacia lo concreto, «atrapada en la espiral del entendimiento reflexivo», siempre "negativo ante sí mismo», extinguiéndose en un irreprimible anhelo (Sehnsucht $)^{10}$ que pudiera desembocar en la locura ${ }^{11}$. El no-yo no es una abisal egofanía inversa, envés del yo donde confluyen las sendas no holladas que le tentaran, mosaico de potenciales obliterados, no naufragios en el lúgubre panteón en que se desmigan las cartas nunca abiertas, un hormiguero lleno de horror y de impías farsas sobre espejos lascivos e indolentes. La enantiosis convoca a la integración, el contrahaz no es egófobo, es el promisorio entorno ontológico que reclama al yo a reunión en un Espíritu total sin exosfera.

El alma bella tejida en Hyperión como figura del Espíritu fuerza a la identidad del yo consigo mismo, abrazando el universal vacío, y en la paridad de

\footnotetext{
${ }^{10}$ Hegel, G. W. F. (1836). "Vorlesungen über die Geschichte der Philosophie”. Georg Wilhelm Friedrich Hegel's Werke: Vollständige Ausgabe durch einen Verein von Freuden des Verewigten III, Berlín: Duncker und Humblot, pp. 644-645: «Die Extravaganz der Subjektivität wird häufig Verrücktheit; bleibt sie im Gedanken, so ist sie im Wirbel des reflektirenden Verstandes befangen, der immer gegen sich negative ist» («La extravagancia de la subjetividad deviene con frecuencia locura; permanece en el pensamiento, atrapada en la turbulencia del entendimiento reflexivo, siempre negativo ante sí mismo»).

${ }^{11}$ Hirsch, E. (1973). "Die Beisetzung der Romantiker in Hegels Phänomenologie”. Materialen zu Hegels "Phänomenologie des Geistes». Ed. Hans Friedrich Fulda - Dieter Henrich, Frankfurt am Main: Suhrkamp Verlag, pp. 245-275.
} 
la subjetividad finita y el yo absoluto halla fundamento el totum armónico. La autoconciencia retorna a su "refugio más íntimo», ante el que desaparece toda exterioridad, torna a la intuición del «yo = yo» en la que éste es "toda esencialidad y toda existencia ${ }^{12}$. La identidad abstracta subviene, entonces, del desdoblamiento del alma bella en dos facies intuitivas con el mismo contenido pero diversa dimensión formal, universal la primera, individual la segunda: conciencia del deber (intuición de la universalidad del deber como dehiscencia propia, no como esencia de una sittliche Wirklichkeit -la conciencia del deber infunde la esencia universal contenida en ella misma-) y autoconciencia (intuición refleja: reconocimiento de sí en la conciencia del deber; autodeterminación moral del alma bella sin injerencia externa que la diviniza en su incondicionalidad. La autoconciencia afora en la conciencia del deber su genuina interioridad como plena realidad ética autodeterminante). La schöne Seele es lo divino que se intuye a sí en autoconciencia puesta por el deber ser universal. En esa intuición descansa su inaparente infinitud.

El sentimiento de yo que instila la autoconciencia se objetiva mediante la acción que lo exterioriza (objetivación exergónica de la subjetividad en una existencia finita, plegada a un concretum espacio-tiempo), mas la asunción por la autoconciencia de su finitud la alejaría de la intuición de sí como su propio contenido (sólo la Idea es auténtica síntesis de finitud e infinitud, ésta no se abona a una subjetividad transcendental por desprovista del carácter absorbente -aufzehren-o asimilativo que pesa sobre la infinitud contra toda solución de yuxtaposición a lo finito). El temor a singularizarse en los actos es vector de pasividad en el alma bella, la abstención de toda acción, individualizante por circunscrita a un plexo espacio-temporal o supeditada a factores biogénicos, históricos, culturales,..., perseverando tediosamente en una identidad oblicua, sesgada, que coarta el impulso activo suplente del respeto a la objetividad del deber. La simple vanidad encubre la akrasia en una voluble conciencia mermada, reacia a la confesión de los móviles patógenos que guiaran sus decisiones en posición alienada del universal (los motivos inéditos, el placer suspendido en la

\footnotetext{
${ }^{12}$ Hegel, G. W. F. (1952). "Phänomenologie des Geistes". Georg Wilhelm Friedrich Hegel Sämtliche Werke: neue kritische Ausgabe V, Hamburg: Felix Meiner, p. 461: "Wir sehen hiemit hier das Selbstbewußtsein in sein Innerstes zurückgegangen, dem alle Äußerlichkeit als solche verschwindet, -in die Anschauung des Ich = Ich, worin dieses Ich alle Wesenheit und Dasein ist» («La autoconciencia ha retornado a su refugio más íntimo, ante el que se esfuma toda exterioridad como tal, a la intuición del yo = yo, en la que el yo es toda esencialidad y toda existencia»).
} 
imaginación, no agotado en su satisfacción, que rememora el oso de Croisset en La educación sentimental).

La inactividad es la actitud de una conciencia inobjetivable y reticente a la intersubjetividad en dramática autoidentidad inconcreta sostenida contra la potestad efectiva del Espíritu sobre la realidad (la epojé anergónica deja abierta la vía de realización al lenguaje y al juicio discursivo sobre los actos de otras autoconciencias singularizadas. El aislamiento del alma en su beldad es trágico). Inhibida la realización en el marco integral del Espíritu universal que desborda toda individualidad vinculándola a las demás, el alma bella queda paradójicamente singularizada como una subjetividad huérfana de contenido contracto (profesa un Dasein estanco) cuya única aptitud sería la pasiva rebeldía ante la universalidad de la sustancia espiritual ${ }^{13}$ (ese alma es la necrópolis del $I$ would prefer not to desde la que Bartleby entona la atribulada antífona de los mensajes de vida que se apresuran a la muerte -on errands of life...-).

El alma absorta en la propia belleza se retroalimenta por identidad hueca, el nocivo feedback que abduce a cuanto perece ofuscado en la melancolía de su sola resonancia interior. La vis poética le permitirá asomar a la belleza natural, y en ella estalla la melodía salvaje que evoca Endymión, la fruición eterna que alza el paño mortuorio del espíritu ensombrecido y jamás declinará en la nada ${ }^{14}$. La autoconciencia sale momentáneamente de sí, abandona la apariencia de finitud que enmascara la infinitud de su dignidad divina (también, en una transgresión del estatismo entelejético, la nóesis noéseos, sin cejar en su autopensamiento, toma nula distancia de sí en la kénosis para abrir el escenario ontológico de la creación, contemplándose en ella, como un instante de naturaleza anterior contemplara eviternamente en sí a la creación en la completa amplitud de su devenir espaciotemporal), para reingresar en la totalidad armónica que se determina a sí misma, reconociéndose en ella, porque, incapaz de percibir lo incondicionado, ha dejado de ser fundamento de la armonía holística en la confusa identidad de su finita subjetividad con el yo absoluto. Aflora la anfipatía ectópica del yo, la afirmación disruptiva originaria del yo como sujeto o como objeto, abocada al ser absoluto y a la participación (Hölderlin), no a la unión de la unión y la no-unión (Verbindung der Verbindung und der Nichtverbindung), reformulada como identidad de la identidad y la no-identidad, que preside la concepción hegeliana de la infinitud (la antítesis Glauben / Wissen, se escora del lado del saber en la absolutización de

\footnotetext{
${ }^{13}$ Pöggeler, O. (1956). Hegels Kritik der Romantik, Bonn: H. Bouvier und Co., pp. 94ss.

${ }^{14}$ Keats, J. (2015). Endymion, Madrid: Visor.
} 
la finitud, precipitándose por la vertiente opuesta el ansia de infinitud, la sed del Dios incognoscible que rebasa las fronteras del entendimiento como una suerte de feliz ilusión empírica).

En la autoconciencia, el hombre se apartó de lo divino (vestigios neoplatónicos de la procesión del noûs en nóesis reflexiva desde el Uno árquico, que está más allá del pensamiento de sí ${ }^{15}$, la conciencia de sí es una caída ontológica a la finitud desde el estado divino, una catábasis hipoteósica instigada por la ávida inclinación a sí que vulnera el rigor de la unidad. El carácter incoativo de la razón acentúa la presencia de la conciencia a sí misma como vía posibilitatoria ${ }^{16}$. En los dioses, el hombre uranio se representa a sí en el cénit del proscenio creatural ${ }^{17}$, y la inquietud artística sería la anámnesis inducida por la necesidad que acucia al hombre de contemplar su propia belleza. Frente al arte, la filosofía no es más que una «ciega exigencia de progreso irresolutivo», jamás podrá elevarse la razón sobre

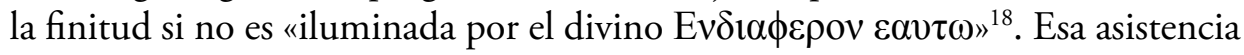
iluminadora no es obviamente en Hölderlin un auxilio epistémico sino poético (el silencioso verbo interior, el lógos endiathetós) que ensalza la naturaleza como lo absoluto excluyente de la muerte y el tiempo (la muerte parasita a los entes finitos y los moldea, el tiempo estraga la finitud, dándole forma en su seno). El

${ }^{15}$ Halfwassen, J. (1999). Hegel und der spätantike Neuplatonismus, Bonn: Bouvier Verlag, pp. 40ss.

16 Una explicación noológica: la fuerza de imposición, la noergia de Zubiri, fuerza ínsita que a la realidad le brota de sí, imponiéndose a la inteligencia sentiente, poseyéndola, emana ahora de la misma inteligencia (la religación sería, en la autoposición sentiente, la dimensión ontológica de su propia conciencia, o la realidad de ésta, apoderándose del sujeto consciente), pero el momento noemático no está coartado, reportando un índice de alteridad: la afecciónnóesis y el noema en la aprehensión o intelección sentiente de sí como actualidad respectiva (ser que presume una realidad fundante) por la inteligencia revierten en la noergia que malogra la auténtica identidad, la suidad, por religación.

17 Sale, W. M. (1984). "Homeric Olympus and Its Formulae". The American Journal of Philology Vol. 105, pp. 1-28. En la épica homérica, "ó oủ $\rho \alpha v o ́ c$ " aludiría al cielo natural sin mención de los dioses que lo habiten.

18 Hölderlin, F. (1846). "Hyperion oder der Eremit in Griecheland". Friedrich Hölderlin's Sämtliche Werke I, Stuttgart-Tubinga: J.G. Gottascher Verlag, p. 77: «Aus bloßem Verstande kömmt keine Philosophie, den Philosophie ist mehr, denn nur die beschränkte Erkenntniß des Vorhandnen. Aus bloßer Vernunft kömmt keine Philosophie, denn Philosophie ist mehr, denn blinde Forderung eines nie zu endigen den Fortschritts in Vereinigung und Unterscheidung eines möglichen Stoffs. Leuchtet aber das Göttliche Ev $\delta 1 \alpha \phi \varepsilon \rho o v \varepsilon \alpha v \tau \omega$, das Ideal der Schönheit der strebenden Vernunft, so fordert sie nicht blind, und weiß warum, wozu sie fordert» (la razón persigue la armonía global a través del ideal divino de belleza. No podría alzarse la razón sobre la finitud en su impulso ciego de discriminación y reunificación, si no es por la divina iluminación, que no proviene de ella misma sino que emana de la poesía). 
olvido de sí mismo en la contemplación de la naturaleza anonada la autoconciencia, impeliendo a la participación en la eternidad (ser uno con el todo es la vida de la divinidad). Una identidad zozobrante, carente del blindaje ontológico que demanda la coalescencia de impresiones estabilizadora de un nítido yo en el curso vital, el tegmento óntico constante de acedía y euforia, dolor y placer, pasiones y sensaciones, que Hume sancionara en el desahucio del ego criboso, asediado por sombras que no custodian nada, letales para la conciencia de esa socavada identidad que sólo es un ascua mnémica, un visado mnemónico solapado a la sucesión.

\section{3.- Epipsychidion: el alma bella nace de sí misma}

La tesis onto-epistemológica que sitúa el origen de las formas en el Espíritu subjetivo (totalidad de formas objetivas invocadas en la verdad del sujeto como Espíritu), orbitando en torno al dilema de la primacía del yo o la naturaleza, subyace en ese hermoso canto de 604 versos consagrado al alma nacida del alma que Percy B. Shelley escribiera, un año antes de su muerte, a la par que el ensayo $A$ Defence of Poetry, el año de Adonais, la elegía pastoral a Keats en la línea tradicional de Lycidas, compuesta probablemente sobre el modelo de la décima égloga de Virgilio en la primavera boreal de 55 estrofas (Spenserian stanzas).

Aunque más próximo en el narcisismo psicológico y la erótica de corte platónico al yo romántico que anhela la libertad prometida por la Revolución que al idealismo alemán, se advierte también en Shelley una firme vocación de subjetividad absoluta, aglutinante de las diversas facetas de la vida humana, una razón demiúrgica que irradia sobre tenues contornos en suave balanceo dialéctico, del "día a la noche», de «la primavera al invierno, o la esperanza a la pena» ${ }^{19}$.

En tanto la aspiración a objetos sensibles, primordialmente diversos de los noéticos o conceptuales, vise como actividad objetiva, el Espíritu quedará huérfano de sí, sumido en la finitud, postrado en la comprensión genética-histórica I dialéctica-relacional de la realidad, relegada en su incompletud. La distinción de todos los objetos en general fractura el orden cósmico, abortando una verdad

19 Shelley, P. B. (2008). Epipsychidion. Edición bilingüe de Rafael Lobarte, Madrid: Visor, v. 73-74, p. 34:

Winter by Spring, or Sorrow by swift Hope» 
total sobre la realidad en su integridad, sin embargo, contra Hegel, el romántico inglés, afín a la tesis de Sydney que aboga por el servicio de la poesía al deleite emocional e intelectual frente a la interdicción platónica por falacia e irracionalidad o la censura de Thomas L. Peacock a la misión poética en una era positivista (The Four Ages of Poetry, 1820), no restringe lo real a racional, en consonancia con la naturaleza y competencia de una razón, que, en su finitud, deja una vacante opaca, el horizonte inalcanzable del en sí absoluto, atrio insondable del nóumeno bajo égida poética ${ }^{20}$, que insta a una clase de intuición no sensible:

«In her mild lights the starry spirits dance,

Under the lightnings of the soul -too deep

For the brief fathom-line of thought or sense» ${ }^{21}$

El espíritu se inflama en su diáfana virtud, sin agostarse en la soledad del auto-encuentro persigue una visión perdida de sí a través de sendas retraídas en

20 También la admonición de la distinción kantiana entre ser y deber ser tiene especial relevancia en Hegel. El desajuste estructural entre teoría y praxis, la luxación en el orden kantiano de pensamiento y ser, abocaría al fracaso en la plena resolución del deber ser, el imperativo categórico que quiere imponerse como rigurosamente efectivo. A esa maliciosa dicotomía se suma la diferenciación entre entendimiento (facultad cognoscitiva proyectada a lo fenoménico, en su finitud y limitación) y razón (en fuga antinómica o paralogista hacia la utopía transcendental, el ideal incondicionado). Una delusoria búsqueda de la totalidad por la tesitura formalmente infinita de la razón en su impulso metacognitivo (defecto de intuición inteligible), pero materialmente finito y limitado en el ejercicio de su función cognitiva (intuición sensible supeditada a las formas a priori de la sensibilidad interna y externa), que haría de la filosofía una párvula vocación de saber, no una ciencia, auténtica Wissenschaft (la filosofía como crítica, no saber, absoluto, de la totalidad de lo real como sistema racional). En conexión con ese último dualismo se hallaría la distinción fenómeno (objeto de entendimiento) / noúmeno (ensidad metaepistémica que estimula la anábasis prosilogística de la razón). Estas díadas irreductibles en el programa kantiano conducirían a la 'finitización' del infinito (compendiadas en el díptico finitud / infinitud, un infinito distinto y separado de lo finito se convertiría, arguye Hegel, en finito). El rumbo sistemático del saber y el devenir ontológico (la realidad como devenir) se concretan en tres momentos: identidad indiferenciada (momento abstracto de unidad de sujeto y objeto, que no se oponen aún, si bien se presentan en estructura y forma que permite relacionarlos en antítesis), identidad fisurada (ruptura de identidad, momento dialéctico o racional-negativo de disociación polar, extrusión de la oposición sujeto-objeto, pensar y ser, generativa-promotora del cambio), identidad refundada (distensión polar con reajuste o reencuentro de contrarios, momento racional-positivo de identidad de la realidad consigo misma en coda subjetiva, integrando la multitud de objetos).

${ }^{21}$ Shelley, P. B. (2008). Epipsychidion, v. 87-90, p. 36. 
la niebla por las que vagan auras ciegas, vacías como exuvias rasgadas por la luz ácima de la tarde (fantasmas de ecdisis que transfiguraron almas) o ropas yermas de ahogados que reptan en la orilla postulando una desnudez inútil que repele la caricia. Desciende a un río hosco. Sus aguas, pálidas y temblorosas, le sumergen en la noche. El sueño es el pasadizo subterráneo entre la existencia descarnada y la idílica, las dos dimensiones del espíritu, natural y sobrenatural. Como en Alastor, el Espiritu de la Soledad se posa sobre verdades extrañas que sajan una tierra incógnita, signos aluviales de una recóndita región de la naturaleza en la que anida el mal, libado el umbral de la muerte (la obscena metafísica del umbral abre el ser a una hermenéutica icónica o metafórica). El viaje a la raíz del mundo natural. Donde ya no se divisa el mar y la tierra semeja una vasta esfera de sombra, ingrávida en la ácida sima del cielo, el vacío se corrompe sosteniendo aún trémulos fuegos macilentos que caminan hacia la ruina, luciérnagas en trance de extinción alumbrando en su colapso el Espíritu del mundo. Y el día se volverá noche, la luz derruida óxido, apenas negras oraciones y vuelos febriles de libélulas sobre las sordas jerarquías del polvo. La tarde se volverá noche, y la noche esparcirá sus demonios...

La simbiosis objeto-sujeto revela la feraz intensión del ser. Hegel acomete la búsqueda de una unidad óntica hadal, anterior al desgarro lógico-metafísico sujeto-objeto, hallándola incipientemente en el pensamiento de la vida pura, premonición de la infinitud verdadera, una experiencia transgresora de la reflexividad de la conciencia más allá de toda abstracción sobre el ser del hombre en el contexto religioso en que pudiera gestarse la idea (pensar la vida pura plantea la necesidad de una mediación entre vida finita e infinita) ${ }^{22}$. Una disfótica Aufhebung der Reflexion invita al retorno de la vida sobre sí por elisión de oposiciones. La oposición presupone la posibilidad de la unificación (Hölderlin apunta a una filosofía de la unificación sobre el préstamo elegíaco hèn kai pân en el Brod und Wein), fundamento indemostrable por su independencia de síntesis y medida de los opuestos en su finitud (la unificación se perfila en sucesivas fases como síntesis disolutoria de la oposición vehiculada reflexivamente por la antinomia y como verificación de unificables). La totalidad tematizada en la plenitud vital procura la génesis del principio dialéctico por unión de lo opuesto y de la misma relación para evitar una regresión indefinida. En la poesía tardía de Shelley, el amor a la divina naturaleza, cuya esencia impregna la voluntad de Alastor, traza el luto crepuscular de una búsqueda infructuosa, la unidad quimérica. Truncadas las

${ }^{22}$ Nohl, H. (1966). Hegels Theologische Jugendschriften, Frankfurt am Main: Suhrkamp, p. 146. 
esperanzas de la reina Mab, su máscara godwiana de anarquía ha caído, el lógos sólo incide en la escisión: la realidad sucumbe, minada por tensos antagonismos internos que pervierten lo idílico. No hay desnudez sino abismo, los sentidos embotados convergen en un inconmensurable vacío en que el Espíritu se triza bajo un impulso sombrío y difuso que frustra toda identidad por rebelión contra la vida soñada:

«Mind from its object differs most in this:

Evil from good; misery from happiness...

El contenido actualmente huero con que el objeto se ofrece a la voraz conciencia sensible, la hipnótica variedad de apariencias, se harán patentes tras el tenaz afán de identificación de objeto cognoscible y pensamiento en la percepción

If you divide pleasure and love and thought,

Each part exceeds the whole; and we know not

How much, while any yet remains unshared,

Of pleasure may be gained, of sorrow spared $\aleph^{23}$

Los hechos son nudos de una trama invisible de vínculos, el légamo de esa corriente difusiva de realidad total expandida como Espíritu que todo lo colma y enuncia lo absoluto, sin grietas onto-gnoseológicas, aunque, para el poeta de Field Place, fisuras en el seno del ser concitan la sínquisis

«Diffusion, one serene Omnipresence,

Whose flowing outlines mingle in their flowing ${ }^{24}$

23 Shelley, P. B. (2008). Epipsychidion, v. 174-183, p. 42. O’Neill, M. (1987). "Shelley's Epipsychidion: The Before Unapprehended Relations of Things". Essays in Criticism Vol. 37/2, pp. 135-157.

${ }^{24}$ Shelley, P. B. (2008). Epipsychidion, v. 95-96, p. 36. 
El carácter dialéctico del conocimiento obedece a su metábasis como momento de lo real, no le es originario en relación con lo objetivo sino en tanto que expresión de la norma dialéctica de una realidad procesual, internamente regulada por la contradicción, cuya prognosis se disipa en distinciones inadecuadas que irán inervando las fases abstracta o intelectual, negativo-racional (con sus díadas categoriales: inmediatez-mediación, negación-antítesis,...) y especulativa, en la que cada detalle singular remite a la totalidad; un retículo cuya superficie desafía las isometrías locales y el theorema egregium, emitiendo destellos de infinitud y eternidad a los sentidos.

\section{«A mortal shape indued}

With love and life and light and deity,

And motion which may change but cannot die;

An image of some bright Eternity ${ }^{25}$

Efluvios del Espíritu creador a través de barreras ontológicas que se desvanecen en su turbulencia, la omnitud de la realidad vital como Espíritu incubado en ella, el éxodo hacia la univocidad del ser, tránsito del primer pensamiento inmediato del ser a la determinación del devenir ${ }^{26}$. El Espíritu germina en profusión de formas ambiguas que obtienen su contorno de los residuos ónticos del caos en que se hundiera el hombre prelapsario

«The life that wears, the spirit that creates

One object, and one form, and builds thereby

A sepulchre for its eternity» ${ }^{27}$

La diástasis sujeto-objeto sólo podría franquearse (restañarse) por reducción epistemológica del segundo al primero (polarización subjetiva del objeto y

\footnotetext{
25 Shelley, P. B. (2008). Epipsychidion, v. 112-115, pp. 36-38.

26 Será Heráclito quien concilie a través del hèn pân, a juicio de Hegel, la univocidad eléata del ser con la multiplicidad cósmica, y su progreso necesario consistiría en haber pasado del ser como primer pensamiento inmediato a la determinación del devenir como segundo.

27 Shelley, P. B. (2008). Epipsychidion, v. 171-173, p. 42.
} 
objetivación del Espíritu, identidad en y por el sujeto) y contracción ontológica del ser a pensar (lo verdadero aprehendido como sujeto en la misma medida que como sustancia). Sólo de ese modo, en la tensión óntico-noética y desde la división inicial, se forja un estado de equilibrio en que el pensamiento funde con el mundo enfrentado, comprometida la armonía en el diálogo de contrarios: la oscuridad se cierne sobre cada llama moribunda; la noche, en su madeja de sombras, presagia la luz; semillas de flores feroces despedazadas en un sueño hidrópico, anémicas en su letargo invernal, el albumen áspero como la ternura sombría heredada de las aves escuálidas y los árboles enfermos, aguardan los sones de la tierra bajo el acre aliento del oeste, lánguida criatura que acecha dones póstumos; las hojas muertas sólo hacen inaudible la respiración de lo que ya no remontará la tierra, un manto que no seca los latidos enterrados, cada vez más

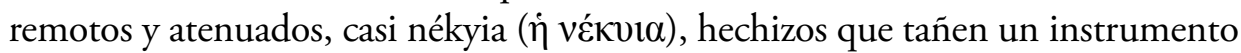
inmóvil, el fúnebre clamor que gravita sobre los turbios engranajes de la noche.

Alma que se engendra a sí misma ${ }^{28}$ en la caligrafía furtiva del azar sobre las intuiciones puras. La imaginación reproductiva transluce el dominio implícito de la mente sobre las imágenes, evocaciones y asociaciones condensadas en símbolos universales ${ }^{29}$. La interiorización de la palabra como imagen privada suscita una memoria propia en su reverberación introspectiva, signos canónicos que abrazan la fijeza de lo externo y transfunden la flaqueza de lo subjetivo, pero la conciencia desiderativa es inapaciaguable, pese a consumir cada objeto no se sacia en su tenebrosa linfa.

En los modos de conciencia directa, no analítica, que tamizan la intuición se insinúan un vigor y un contenido intelectual detonantes del conocimiento de relaciones espacio-temporales, no puramente subjetivas, sino objetivas, $y$ si bien el arte plasma la idea de forma inmediata, en conexión con el material sensible, hendido éste por alguna noción o significado interno, la misma penetración es ya simbólicamente connotativa de la absorción de lo otro por el Espíritu autoconsciente. La fusión de ideas con el acervo sensible es basal en la obra de arte. En la creación, la forma emergente no será comprendida como mera

\footnotetext{
${ }^{28}$ Shelley, P. B. (2008). Epipsychidion, v. 238, p. 46: «Whither 'twas fled, this soul out of my soul».

${ }^{29}$ La naturaleza será después el templo de vívidos pilares del que brotan abstrusas palabras y los bosques de símbolos universales que mortifican al hombre con su familiar mirada en Les Fleurs de Baudelaire.
} 
relación noemática, antes bien, en ella se transparenta toda la pulsión sémica en el objeto mismo unida a su inmediatez sensible.

La causa del naufragio final del arte estriba en su impotencia para sondear por completo el espesor del Espíritu, gestado en la alianza de bondad moral, imaginación y $\operatorname{amor}^{30}$, al no lograr superar plenamente la distinción entre lo interno y lo externo. En connivencia con Hegel, la endogeneidad del Espíritu no es la calidad de lo interno frente a lo externo, sino la profundidad que envuelve a ambos.

Símbolos teóforos fagocitan los sedimentos de una realidad quebrada. User-Maat-Re Setep-en-Re... El rostro de Ozymandias sepultado en la arena, nada a su lado, decadencia e ilimitada ruina. La sigilosa luz de las estrellas desliza sinuosamente por la Duat, despertando, como una hermana sonámbula, a Apofis $^{31}$, que tińe de rojo el cielo al herirlo desde la tiniebla que la embosca. El orden cósmico, la Maat, se ha roto; el navío encallado en el limo que levantó la fuerza destructora, ajena a la miseria humana, es un sarcófago donde maduran lívidas crisálidas surgidas de las cenizas de corazones áridos, y Dat, el reino ocre, un glaucoma frío que empaña el iris solar. En el amnios pútrido flotan niños eviscerados y estériles amuletos. Nepai desova el caos en los ciclos somnolientos del delta, no regresará al vaso ornado del que respiran los muertos. El ka de las ofrendas se ha apagado, inmóvil la rueda del alfarero, todas las almas derrubios en el lodo frígido. Caóticas aguas primordiales niegan la regeneración, un trozo de la mujer alada yace sobre cada altar expoliado augurando un moderno Prometeo que jamás descifrará los arcanos. Lo uno se cierra sobre sí, la realidad absorbida por el fantasma: un océano inerte, sin orillas, ovillado en la oscuridad que no es noche, aún no creada. Cesa la palabra, enmudece el demiurgo, fundiéndose con Nun en el sueño, hay Nun pero no existe, no ve, sólo aúllan máquinas insomnes violando las leyes de la penumbra, el silencio que les imponen los hogares devastados por horas huecas que no se sacian en las clepsidras, aferradas a la lógica perversa de las pesadillas, mezclando toda la inanidad y la histeria mecánica, una vigilia insolente que simula la sed, el desamparo o la desposesión que caben en un cuerpo, en un solo eco sedicioso, repulsa de la muerte y la restitución, adverso a cada plegaria.

${ }^{30}$ Verma, K. D. (1995). The Vision of "Love's rare Universe". A Study of Shelley's Epipsychidion, Lanham: University Press of America, pp. 40ss.

31 Shelley, P. B. (1997). No despertéis a la serpiente. Edición bilingüe de Juan Abeleira y Alejandro Valero, Madrid: Hiperión. 
Signos de ontolisis agudizan la disociación entre pensamiento y sensibilidad. Un alud de sombras erráticas excitadas por espurios resplandores que perforan la noche sin dejar al Espíritu encontrar su centro, hallar la unidad continuamente en sí. Furiosos aleteos de Erinias se oponen a una verdad total y a los designios de un Espíritu residente en sí mismo, prendido a la facticidad de su libertad. Los inferi Dii, deidades tutelares de la hiedra y los frutos negros ${ }^{32}$, hostigando a todas las almas comunes que acuden a borrar los recuerdos en las cenagosas aguas del Érebo (ni la más expeditiva sinécdoque serviría para que su voz escapara de las grutas que las reservan para el juicio). Retorno quiástico, el ciclo dialéctico alterado: lacias aguas no alivian la opacidad del espíritu, exhumado por el frío que refuta su desnudez y gana ser en sus bordes. Sólo la lluvia se fatiga en los colores. Regresa la piedra, más impúdica aún, ya casi lecho, o tumba.

La danza ciega de formas en dispersión retrasa su identidad, haciendo del lienzo terrenal una fugaz orgía de clámides simbólicas en pos de un contenido demudado, porque, dirá Marx después, el desgarramiento y contradicción del fundamento terrenal, segregado de sí como un reino independiente, exige revolucionarlo prácticamente para comprenderlo en sus contrastes. El sentimiento religioso se mantiene incólume, inmanente en una mística mundana que sólo narra ya la relación esencial del hombre consigo mismo y con la naturaleza, dragados los cauces de la interna generalidad, la desvaída estela del hombre abstracto... «Ninguna voz de un ámbito sublime» responde para deshacer «el azar, la duda, lo mudable» ${ }^{33}$. El tiempo del epi-lógos se yergue sobre el límite impuro de memoria y hueso.

\section{Conclusión}

El platonismo fáustico de Shelley alcanza cotas proféticas: el alma humana se alza en momento decisivo de la realidad. La conquista de la cima, abatidos los monstruos que habitan las cumbres, es la materialización del ideal poético, allí donde el Espíritu se arropa en el ser absoluto. La soberanía del alma que se

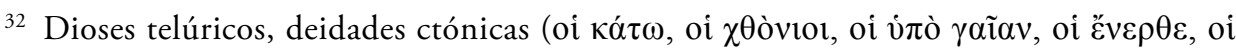

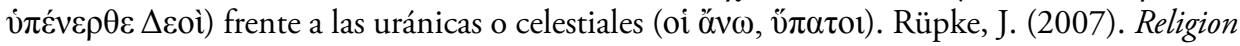
of Romans, Cambridge: Polity Press.

33 Shelley, P. B. (1819). "Hymn to Intellectual Beauty". Rosalind and Helen. A Modern Eglogue with Other Poems, London: C. and J. Ollier, lines 25ss.
} 
eleva a la eternidad desde la conciencia estética hará del entorno su reflejo (el yo, no absoluto sino pendular, en oscilante identidad, clave de todo lo circundante), pero el aislamiento en el paraíso epipsíquico no podrá eludir el dolor de la realidad.

Supura la llaga del Espíritu en su egresión psíquica de la naturaleza como latente idealidad de la materia por su capacidad de asociarse a cualquier forma de ser, despojada de todo contenido finito, y como en la Fenomenología, la represión de la pasión individual enfrentada a un sistema impersonal de símbolos (esencia cautiva del mundo) pasa por el dominio de un particular sentimiento de sí en enajenada inadaptación a elementos materiales de edificación objetiva de la libertad que delatan el estado de conciencia oscura en su matriz sensible desde el que acaecerá la exteriorización del Espíritu. El alma acabará desplegando sobre el mundo sus exigencias bajo modos de conciencia directa, la autoconciencia es la caída de una subjetividad marginada de la infinitud por adhesión a una naturaleza objetivada que la arrastra al tiempo, la lepra gris que roe el orbe creatural, expulsada de la eternidad, sólo accesible a través del sentimiento. La oposición entre la densidad intencional del sujeto y el cariz abstracto del bien se diluye en la premisa de una nueva sustantividad moral que, conminatoria de la forma de representación obstructiva de la simple vivencia, preludia el reencuentro utópico con la naturaleza tras la alegórica muerte del yo enajenado de ella (desnaturalizado) por la enardecida razón (catabiosis, declive ontológico a la finitud). La expiatoria muerte de Empédocles, arrojado al cráter del Etna (inmolación en la entraña del mundo natural del que se exiliara) para resurgir, purificado (transición de lo subjetivo a lo objetivo, sin supresión de elemento subjetivo, inserto en un plano relacional superior), fuera del tiempo de los reyes, en la apología de Hölderlin, se torna epipsicosis en el poema de Shelley, autogénesis psíquica sobrepuesta a la vacilante identidad en la abrupta fluctuación polar (sujeto-objeto) de un alma egógena que con pudorosa turbación se desprende del último velo que la cubre.

Lejos de la esencia autoponente del yo como incondicionado que erigiría a la subjetividad absoluta en unidad original (línea fichteana que criba la esencia del yo en su propio ponerse a si mismo por rígida autoidentidad), un anhelo de retorno sin fin al prístino ser manifiesto en la belleza punza al alma epipsíquica en la obra de Shelley, cuarteada por ecos hegelianos y vetas del Urteil und Sein: la proposición en la que el yo límbico afirma su egocidad es enunciado ontológico 
y, precisamente por tal, bascula en la dualidad (ontológica) sujeto-objeto ${ }^{34}$, $\sin$ deposición de cisma. "Ich bin Ich» enfrenta copulativamente al yo-sujeto con el yo-objeto, el yo subyectado se afirma a sí en obyacencia, irrumpe la autoconciencia por reconocimiento del yo en apostema, en oposición a sí mismo o a través de la propia escisión, sin solución unitaria de ser (la renovada identidad consigo mismo aboca a la alteridad en la forma objetivada de yo con el sentido pre-reflexivo de ser para si: la intratemporalidad netamente subjetiva que fundase todo orden temporal reflexivo-objetivo pasaría por el carácter intrínsecamente consciente de la autoconciencia). La unidad ideal se hace presente por una vía distinta a la conciencia de sí, la sintaxis del ser absoluto en su dimensión poética. La sombra de una fuerza ignota agita el cosmos, y en esa conmoción vibra la belleza como espejismo de la totalidad orgánica a la que aspira el alma surgida de sí, de su inmersión en la finitud. La epipsicosis no es una simple transmigración, una metempsicosis depurativa de residuos imaginativos o mnemónicos ligados a la experiencia sensible, renacer psíquico al margen de la coyuntura temporal de la memoria sin la que ésta pierde toda expectativa de subsistencia y relevancia en la génesis de la identidad individual, sino la inflexión entre la soledad idílica de Hyperión y la agnosia onírica de Endymión.

Si Hölderlin exhorta a quienes buscan lo más elevado, «la profundidad del saber [...], en la oscuridad del pasado, en el laberinto del futuro, en las

34 Hölderlin, F. (1962). Urteil und Sein. Friedrich Hölderlin: Sämtliche Werke IV, Stuttgart: Hölderlin-Archiv der Württembergischen Landesbibliothek, p. 227: «Wenn ich sage: Ich bin Ich, so ist das Subjekt (Ich) und das Objekt (Ich) nicht so vereiniget, daß gar keine Trennung vorgenommen werden kann, ohne, das Wesen desjenigen, was getrennt warden soll, zu verletzen; im Gegenteil das Ich ist nur durch diese Trennung des Ichs vom Ich möglich. Wie kann ich sagen: Ich! Ohne Selbstbewußtsein? Wie ist aber Selbstbewußtsein möglich? Dadurch daß ich mich mir selbst entgegensetze, mich von mir selbst trenne, aber ungeachtet dieser Trennung mich im entgegengesetzten als dasselbe erkenne. Aber in wie ferne als dasselbe? Ich kann, ich muß so fragen; denn in einer andern Rücksicht ist es sich entgegengesetzt. Also ist die Identität keine Vereinigung des Objekts und Subjekts, die schlechthin stattfände, also ist die Identität nicht = dem absoluten Sein» («Si yo afirmo: yo soy yo, entonces el sujeto (yo) y el objeto (yo) no están unidos de tal modo que ninguna separación pueda ser percibida, sin dañar la esencia de éste que ha de ser separado; al contrario, el yo sólo es posible mediante esta separación del yo por el yo. ¿Cómo puedo decir «yo» sin autoconciencia? ¿Pero cómo es posible la autoconciencia? Precisamente porque yo me opongo a mí mismo, me separo de mí mismo, y a pesar de esta separación me reconozco en los opuestos como esto mismo. ¿En qué medida como esto mismo? Yo puedo, así que debo inquirir; pues el yo se opone a sí mismo en otra perspectiva. Por consiguiente, la identidad no es ninguna unión de objeto y sujeto que tenga lugar sin más, y así la identidad no es = al ser absoluto»). 
tumbas o más allá de las estrellas» ${ }^{35}$, a designarlo belleza, el poeta de Sussex llora la desierta faz de un mundo abandonado por ella, transido por el temor y el sueño, y en su disforia vislumbra el estrecho lazo entre el ser infinito y la belleza: el entendimiento, amenazado por aflicciones vestigiales, combate la finitud que lo cerca, y la razón se extenúa en el constante impulso de unificar inconciliables; ese impulso sería vano, no hallaría la armonía global del mural finito, si no estuviera imbuido de una luz divina externa, la belleza que sacraliza el pensamiento, inmanente a cada ente natural, una voz que sólo se oye en el rumor de la sangre, cuando el «vaivén de los latidos» semeja el «vivo oleaje del ser» ${ }^{36}$, no un océano yermo o una tierra que exhalando el hedor de la muerte bajo un mórbido eclipse de astros marchitos ya no sanará.

${ }^{35}$ Hölderlin, F. (1846). Hyperion oder der Eremit in Griecheland. Friedrich Hölderlin's Sämtliche Werke I, Stuttgart-Tubinga: J.G. Gottascher Verlag, p. 48: «O ihr, die ihr das Höchste und Beste sucht, in der Tiefe des Wissens, im Getümmel des Handelns, im Dunkel des Vergangenheit, im Labyrinthe der Zukunft, in den Gräbern oder über den Sternen! Wißt ihr seinen Namen? Den Namen daß, das Eins ist und Alles? Sein Name ist Schönheit» («iOh vosotros, los que buscáis lo más elevado y lo mejor en la profundidad del saber, en el tumulto del comercio, en la oscuridad del pasado, en el laberinto del futuro, en las tumbas o más arriba de las estrellas! ¿Conocéis su nombre?, ¿El nombre de lo que es uno y todo? Su nombre es belleza»).

36 Shelley, P. B. (2008). Epipsychidion, v. 315, p. 50: «The moving billows of my being». 


\section{Bibliografía}

Abrams, Meyer H. (1996). El espejo y la lámpara: Teoría romántica y tradición crítica, Barcelona: Barral Editores.

Agnes, Peter (1993). "A Hermeneutical Reading of 'Epipsychidion'”. Keats-Shelley Journal Vol. 42, Bicentenary Tribute to the Achievement of Percy Bysshe Shelley, pp. $120-127$.

Baum, Manfred (1976). "Zur Vorgeschichte des Hegelschen Unendlichkeitsbegriffs". Hegel-Studien Vol. 11, pp. 89-124.

Bloom, Harold (1974). Los poetas visionarios del romanticismo inglés, Barcelona: Barral Editores.

Cruzalegui, Patricia (2001). El platonismo romántico de Shelley, Perú: Pontificia Universidad Católica de Perú.

Dod, Elmar (1985). Die Vernünftigkeit der Imagination in Aufklärung und Romantik. Eine komparatistische Studie zu Schillers und Shelleys ästhetischen Theorien in ihrem europäischen Kontext, Tübingen: Max Niemeyer.

Hall, Jean (1992). “The Divine and Dispassionate Selves: Shelley's Defence and Peacock's The Four Ages". Keats-Shelley Journal: Keats, Shelley, Byron, Hunt, and Their Circles Vol. 41, pp. 139-163.

Hall, Spencer (1983). "Power and the Poet: Religious Mythmaking in Shelley's 'Hymn to Intellectual Beauty'”. Keats-Shelley Journal Vol. 32, pp. 123-149.

Hauser, Arnold (1968). Historia social de la literatura y el arte II, Madrid: Ediciones Guadarrama.

Hegel, Georg W. Friedrich (1952). "Phänomenologie des Geistes”. Georg Wilhelm Friedrich Hegel Sämtliche Werke: neue kritische Ausgabe V, Hamburg: Felix Meiner.

Hirsch, Emanuel (1973). “Die Beisetzung der Romantiker in Hegels Phänomenologie”. Materialen zu Hegels "Phänomenologie des Geistes». Ed. Hans Friedrich Fulda y Dieter Henrich, Frankfurt am Main: Suhrkamp Verlag, pp. 245-275.

Hölderlin, Friedrich (1962). Urteil und Sein. Friedrich Hölderlin: Sämtliche Werke IV, Stuttgart: Hölderlin-Archiv der Württembergischen Landesbibliothek.

Knapp, John (1999). “The Spirit of Classical Hymn in Shelley's 'Hymn to Intellectual Beauty'”, Style Vol. 33, pp. 43-66.

Kucich, Greg (1991). Keats, Shelley, and Romantic Spenserianism, Pennsylvania: Pennsylvania State University Press. 
Mahoney, John L. (1990). “Teaching 'To a Sky-Lark' in Relation to Shelley's Defense”. Approaches to Teaching Shelley's Poetry. Ed. Spencer Hall, New York: MLA, pp. 83-85.

O’Neill, Michael (i987). "Shelley's Epipsychidion: The Before Unapprehended Relations of Things". Essays in Criticism Vol. 37, Núm. 2, pp. 135-157.

Pöggeler, Отto (1956). Hegels Kritik der Romantik, Bonn: H. Bouvier und Co.

Reiman, Donald H. \& Fraistat, Neil (2002). "Hymn to Intellectual Beauty”. Shelley's Prose and Poetry, New York: Norton and Co.

Rüpke, Jörg (2007). Religion of Romans, Cambridge: Polity Press.

Shelley, Percy Bysshe (2008). Epipsychidion, Madrid: Visor.

Shelley, Percy Bysshe (1891). A Defence of Poetry. Ed. Albert S. Cook, Boston: Ginn $\&$ Co.

Verma, Kamal V. (1995). The Vision of "Love's rare Universe”. A Study of Shelley's Epipsychidion, Lanham: University Press of America.

RECIBIDO: 22/I I/20I 8

ACEPTADO: I6/02/2019

Este trabajo se encuentra bajo una licencia de Creative Commons ReconocimientoNoComercial-SinObraDerivada 4.0 
